\title{
A common variant upstream of the $P A X 6$ gene influences islet function in man
}

\author{
E. Ahlqvist • F. Turrini $\cdot$ S. T. Lang $\cdot$ J. Taneera $\cdot$ Y. Zhou $\cdot$ P. Almgren $\cdot$ O. Hansson • \\ B. Isomaa • T. Tuomi • K. Eriksson • J. G. Eriksson • V. Lyssenko • L. Groop
}

Received: 19 January 2011 / Accepted: 9 August 2011 /Published online: 16 September 2011

(C) Springer-Verlag 2011

\begin{abstract}
Aims/hypothesis Impaired glucose tolerance and impaired insulin secretion have been reported in families with PAX6 mutations and it is suggested that they result from defective proinsulin processing due to lack of prohormone convertase $1 / 3$, encoded by PCSK1. We investigated whether a common PAX6 variant would mimic these findings and explored in detail its effect on islet function in man.

Methods A PAX6 candidate single nucleotide polymorphism (rs685428) was associated with fasting insulin levels in the Diabetes Genetics Initiative genome-wide association
\end{abstract}

Electronic supplementary material The online version of this article (doi:10.1007/s00125-011-2300-8) contains peer-reviewed but unedited supplementary material, which is available to authorised users.

E. Ahlqvist $(\bowtie) \cdot$ F. Turrini $\cdot$ S. T. Lang $\cdot$ J. Taneera $\cdot$ Y. Zhou

P. Almgren · O. Hansson • V. Lyssenko • L. Groop

Department of Clinical Sciences, Diabetes and Endocrinology,

Lund University, CRC at Skåne University Hospital,

20502 Malmö, Sweden

e-mail: Emma.Ahlqvist@med.lu.se

F. Turrini

Department of Medicine, Verona University,

Verona, Italy

B. Isomaa $\cdot$ T. Tuomi $\cdot$ J. G. Eriksson

Folkhälsan Research Centre,

Helsinki, Finland

B. Isomaa

Department of Social Services and Health Care,

Jakobstad, Finland

T. Tuomi

Department of Medicine, Helsinki University Central Hospital, and Research Program of Molecular Medicine,

University of Helsinki,

Helsinki, Finland study. We explored its potential association with glucose tolerance and insulin processing and secretion in three Scandinavian cohorts $(N=8,897$ individuals). In addition, insulin secretion and the expression of $P A X 6$ and transcriptional target genes were studied in human pancreatic islets. Results rs685428 $\mathrm{G}$ allele carriers had lower islet mRNA expression of PAX6 $(p=0.01)$ and PCSK1 $(p=0.001)$ than AA homozygotes. The $\mathrm{G}$ allele was associated with increased fasting insulin $\left(p_{\text {replication }}=0.02, p_{\text {all }}=0.0008\right)$ and HOMA-insulin resistance $\left(p_{\text {replication }}=0.02, p_{\text {all }}=\right.$ 0.001 ) as well as a lower fasting proinsulin/insulin ratio

K. Eriksson

Department of Clinical Sciences, Clinical Vascular Disease Research, Skåne University Hospital, Lund University, Malmö, Sweden

\section{J. G. Eriksson}

Department of General Practice and Primary Health Care, Helsinki University,

Helsinki, Finland

\section{J. G. Eriksson}

Vasa Central Hospital,

Vasa, Finland

\section{J. G. Eriksson}

National Institute for Health and Welfare,

Helsinki, Finland 
$\left(p_{\text {all }}=0.008\right)$ and lower fasting glucagon $(p=0.04)$ and gastric inhibitory peptide (GIP) $(p=0.05)$ concentrations. Arginine-stimulated $(p=0.02)$ insulin secretion was reduced in vivo, which was further reflected by a reduction of glucose- and potassium-stimulated insulin secretion $(p=$ 0.002 and $p=0.04$, respectively) in human islets in vitro. Conclusions/interpretation A common variant in PAX6 is associated with reduced PAX6 and PCSK1 expression in human islets and reduced insulin response, as well as decreased glucagon and GIP concentrations and decreased insulin sensitivity. These findings emphasise the central role of PAX6 in the regulation of islet function and glucose metabolism in man.

Keywords Genetic association · Incretin · Insulin · Insulin processing $\cdot$ Insulin secretion $\cdot$ Meta-analysis $\cdot$ PAX6 .

PCSK 1 - Proinsulin · Type 2 diabetes

$\begin{array}{ll}\text { Abbreviations } & \\ \text { AIR } & \text { Acute insulin response } \\ \text { BPS } & \text { Botnia Prospective Study } \\ \text { DGI } & \text { Diabetes Genetics Initiative } \\ \text { DIAGRAM+ } & \begin{array}{l}\text { Diabetes Genetics Replication and } \\ \text { Meta-analysis Consortium }\end{array} \\ \text { EC } & \text { Endogenous control } \\ \text { GIP } & \text { Gastric inhibitory peptide } \\ \text { GLP } & \text { Glucagon-like peptide } \\ \text { HBCS } & \text { Helsinki Birth Cohort Study } \\ \text { HOMA-IR } & \text { HOMA-insulin resistance } \\ \text { LD } & \text { Linkage disequilibrium } \\ \text { MEIS2 } & \text { Meis homeobox 2 } \\ \text { MM } & \text { Malmö Men } \\ \text { PAX6 } & \text { Paired box 6 } \\ \text { PC } & \text { Prohormone convertase } \\ \text { PDX1 } & \text { Pancreatic and duodenal homeobox 1 } \\ \text { PPP } & \text { Prevalence, Prediction and Prevention of } \\ & \text { Diabetes } \\ \text { SNP } & \text { Single nucleotide polymorphism }\end{array}$

\section{Introduction}

Paired box 6 (PAX6) is a key regulator of pancreatic development and a transcription factor for genes involved in glucose homeostasis, including insulin, incretins and prohormone convertases, making the gene that encodes it an interesting candidate for involvement in the pathogenesis of type 2 diabetes and insulin secretion.

Mice that have point mutations in the Pax6 gene, resulting in a truncated PAX6 protein, have disrupted islet morphology and decreased numbers of alpha, beta, delta and pancreatic polypeptide cells and, accordingly, markedly reduced hormone production [1]. Biochemical studies have also demonstrated binding of PAX6 protein to regulatory elements in the glucagon, insulin and somatostatin genes $[1,2]$.

In humans PAX6 mutations cause aniridia, a panocular disorder characterised by complete or partial absence of the iris and malformations of the eye [3]. There have been several reports of $P A X 6$ mutation carriers having abnormal glucose tolerance, and of type 2 diabetes co-segregating with aniridia in families with PAX6 mutations [4-6]. Recently, Wen et al. reported that carriers of a PAX6 R240Stop mutation developed impaired glucose tolerance and/or diabetes with age [6]. Mutation carriers had an increased proinsulin/insulin ratio and reduced insulin response to an OGTT [6]. By generating mice with a corresponding stop-mutation, the authors could demonstrate that PAX6 deficiency reduced the production of prohormone convertase (PC) $1 / 3$ and that the PCSK1 gene encoding $\mathrm{PC} 1 / 3$ is a direct transcriptional target of PAX6 [6]. Confusingly, another study reported that mice lacking Pax6 developed diabetes but had normal PC1/3 levels, making the role of PAX6 in PCSK1 transcription unclear [7].

PAX6 also plays a major role in the production of incretins. In mice, PAX6 is needed for the differentiation of gastric inhibitory peptide (GIP) and glucagon-like peptide (GLP)-1- and GLP-2-producing cells in the intestine [8]. Furthermore, PAX6 regulates the production of GIP and proglucagon [9] as well as the main enzymes involved in GIP, proinsulin and proglucagon processing: PC2 and PC1/3 [2, 10-13]. PAX6 could thus affect incretin levels either by changing the expression of the propeptide genes or the levels of processing enzymes.

In addition, PAX6 has been reported to regulate the levels of pancreatic and duodenal homeobox 1 (PDX1) and GLUT2 in mice [14]. PDX1 plays a crucial role in pancreatic development, beta cell function and transcription of genes involved in metabolism (for review see Kaneto et al. [15]). GLUT2 is a glucose sensor expressed in the pancreas, and mice lacking GLUT2 have a blunted first-phase insulin secretion [16].

In the present study we assessed the effect of a common genetic variant in PAX6 on glucose homeostasis. Using genome-wide association data from the Diabetes Genetics Initiative (DGI) [17] study we identified a single nucleotide polymorphism (SNP; rs685428) that is associated with insulin levels, reduced PAX6 mRNA expression in human pancreatic islets and reduced expression of target genes including PCSK1. A detailed description of the metabolic consequences of the identified variant is provided.

\section{Methods}

Study samples and clinical characteristics Clinical characteristics of the study participants are reported in Table 1. The DGI genome-wide association study has been described in detail [17]. The non-diabetic control participants 
Table 1 Characteristics of the study participants

\begin{tabular}{|c|c|c|c|c|c|}
\hline Variable & DGI (controls) & BPS & PPP & HBCS & MM \\
\hline$N$ & 1,467 & 2,629 & 4,580 & 1,688 & 166 \\
\hline men/women $(n / n)$ & $707 / 760$ & $1,191 / 1,438$ & $2,131 / 2,449$ & $745 / 943$ & $166 / 0$ \\
\hline Age at visit (years) & $58.8 \pm 10.1$ & $52.2 \pm 14.8$ & $47.3 \pm 15.3$ & $61.4 \pm 2.9$ & $65.8 \pm 2.0$ \\
\hline BMI $\left(\mathrm{kg} / \mathrm{m}^{2}\right)$ & $26.6 \pm 3.7$ & $26.5 \pm 4.2$ & $26.2 \pm 4.3$ & $27.1 \pm 4.3$ & $26.9 \pm 3.3$ \\
\hline Fasting glucose (mmol/1) & $5.3 \pm 0.5$ & $5.4 \pm 0.7$ & $5.3 \pm 0.6$ & $5.5 \pm 0.6$ & $6.1 \pm 2.4$ \\
\hline 2 h OGTT glucose $(\mathrm{mmol} / \mathrm{l})$ & $5.6 \pm 1.3$ & $5.4 \pm 0.7$ & $5.2 \pm 1.5$ & $6.9 \pm 1.7$ & $10.7 \pm 5.1$ \\
\hline Fasting insulin (pmol/1) & $47.9 \pm 36.1$ & $54.2 \pm 32.6$ & $44.4 \pm 29.2$ & $69.5 \pm 77.9$ & $87.5 \pm 72.2$ \\
\hline 2 h OGTT insulin (pmol/1) & $259.0 \pm 211.8$ & $314.2 \pm 317.2$ & $224.3 \pm 266.0$ & $502.1 \pm 407.7$ & $448.3 \pm 360.6$ \\
\hline CIR & $174.6 \pm 157.7$ & $193.3 \pm 213.6$ & $211 \pm 4.87$ & $192.5 \pm 4.74$ & $66.96 \pm 3.80$ \\
\hline Fasting total proinsulin (pmol/1) & $10.2 \pm 4.5$ & - & $10.5 \pm 5.5$ & $12.9 \pm 10.8$ & - \\
\hline Fasting intact proinsulin (pmol/l) & - & - & - & $4.7 \pm 4.4$ & - \\
\hline Fasting split proinsulin (pmol/l) & - & - & - & $8.2 \pm 7.3$ & - \\
\hline $2 \mathrm{~h}$ total proinsulin $(\mathrm{pmol} / \mathrm{l})$ & $36.0 \pm 16.1$ & - & $37.9 \pm 20.3$ & - & - \\
\hline HOMA-IR & $1.7 \pm 1.4$ & $1.04 \pm 0.6$ & $1.5 \pm 1.1$ & $2.5 \pm 2.9$ & $3.6 \pm 3.4$ \\
\hline Fasting GIP (pmol/l) & - & - & $34.3 \pm 0.5$ & - & - \\
\hline 2 h OGTT GIP (pmol/l) & - & - & $179.4 \pm 1.9$ & - & - \\
\hline Fasting glucagon (ng/l) & - & - & $70.1 \pm 0.5$ & - & - \\
\hline 2 h OGTT glucagon (ng/l) & - & - & $62.7 \pm 0.4$ & - & - \\
\hline MAF (rs685438 G) & 0.22 & 0.17 & 0.16 & 0.14 & 0.13 \\
\hline
\end{tabular}

Data are means $\pm \mathrm{SD}$

$\mathrm{CIR}$, corrected insulin response; MAF, minor allele frequency

were individuals with no first-degree relatives with type 2 diabetes, fasting plasma glucose $<6.1 \mathrm{mmol} / \mathrm{l}$ and $2 \mathrm{~h}$ glucose $<7.8 \mathrm{mmol} / 1$, originating from Finland (Botnia region) and Sweden (southern Sweden and Skara) [17]. Type 2 diabetes was classified according to the WHO (1999) criteria as fasting plasma glucose $\geq 7.0 \mathrm{mmol} / \mathrm{l}$ or $2 \mathrm{~h}$ glucose $\geq 11.1 \mathrm{mmol} / 1$ during an OGTT. The Prevalence, Prediction and Prevention of Diabetes (PPP) study is a population-based study including $\sim 10 \%$ of the population aged 18-74 years in the Botnia region in Finland.

The Botnia Prospective Study (BPS) is part of the Botnia study, which includes 2,770 non-diabetic family members and spouses of diabetic individuals. Of these, 138 developed diabetes during the follow-up period (median 7.7 years follow-up).

The Helsinki Birth Cohort Study (HBCS) consists of a subset of 1,999 participants, aged 56-70 years, from the original Helsinki birth cohort $(n=8,760)$ that have undergone an OGTT [18]. Of these, 311 individuals had type 2 diabetes.

For these studies, individuals with type 2 diabetes were excluded from the analysis of quantitative traits.

In the Malmö men (MM) study, acute insulin response (AIR) during a glucose-dependent arginine stimulation test was analysed in a subgroup of 168 men from the Malmö Preventive Project study who had impaired glucose tolerance at the screening visit 20 years earlier [19-21]. At the time of the test 70 men had developed type 2 diabetes and were either treated with diet alone (42\%) or with oral hypoglycaemic agents that were discontinued the day before the test.

All participants gave written informed consent and the studies were approved by the local research ethics committees of Lund University, Malmö University Hospital or Helsinki University hospital.

Measurements In the BPS, blood samples were drawn at -10 , 0, 30, 60 and $120 \mathrm{~min}$ of the OGTT, and in the PPP study at 0 , 30 and $120 \mathrm{~min}$. For the BPS, results from the first visit were used. Plasma glucose was measured by glucose oxidase methods. Plasma insulin concentrations were measured using a fluoroimmunometric assay (AutoDelfia, Perkin Elmer, Turku, Finland). In the Botnia PPP study, proinsulin was measured using a human proinsulin RIA (95\% cross-reactivity with 32 33 split proinsulin, no cross-reactivity with 65-66 split proinsulin, insulin or C-peptide) (Millipore, Malmö, Sweden). In the HBCS proinsulin was measured by a two-site immunometric assay (66\% cross-reactivity with 65-66 split proinsulin, no cross reactivity with 32-33 split proinsulin) [22].

GIP was measured using an ELISA kit for total human GIP [100\% cross-reactivity with GIP(1-42) and GIP(3-42)] (Millipore). Glucagon was measured using a radioimmunoassay kit specific for pancreatic glucagon (cross-reactivity with oxyntomodulin $<0.1 \%$ ) (Millipore).

For a detailed description of the measurements in the DGI see [17]. 
The basal HOMA-insulin resistance (HOMA-IR) index was calculated from fasting insulin and glucose concentrations (www.dtu.ox.ac.uk).

Corrected insulin response during OGTT was calculated as in $[23,24]$.

Arginine-stimulated insulin secretion Insulin secretion in response to an acute bolus of arginine was measured at three glucose concentrations (fasting, 14 and $28 \mathrm{mmol} / \mathrm{l}$ ) as previously described [21]. The AIR was calculated from the +2 to $5 \mathrm{~min}$ values using the trapezoidal rule. Potentiation of insulin secretion by glucose was calculated as the slope between AIR at fasting and $14 \mathrm{mmol} / \mathrm{l}$ glucose [21].

Genotyping Genotyping was performed using a TaqMan ${ }^{\circledR}$ assay on the ABI 7900 platform (Applied Biosystems, Foster City, CA, USA). Average genotyping success was $96.9 \%$ and the concordance rate was $99.8 \%$. Hardy-Weinberg equilibrium was fulfilled in all populations.

Human islets Islets were provided by the Nordic Network for Islets Transplantation by the courtesy of O. Korsgren, Uppsala University. All donors had given consent to donate organs for medical research, or alternatively consent was obtained from the closest relative in accordance with the ethics approval by the ethics committees at Uppsala and Lund Universities. The study included islets from 48 donors, six of whom were diagnosed with type 2 diabetes ( 25 women, 23 men), with a mean $( \pm \mathrm{SD})$ age of $55.3 \pm$ 11.6 years, BMI of $26.1 \pm 3.4 \mathrm{~kg} / \mathrm{m}^{2}$, purity $69.5 \pm 16.8 \%$ and $\mathrm{HbA}_{1 \mathrm{c}} 5.8 \pm 0.87 \%(39.9 \pm 9.5 \mathrm{mmol} / \mathrm{mol})$. Islets were either directly subjected to Affymetrix analysis (see below) or collected under a stereomicroscope and preincubated for $30 \mathrm{~min}$ at $37^{\circ} \mathrm{C}$ in $\mathrm{KRB}, \mathrm{pH} 7.4$, supplemented with $10 \mathrm{mmol} / 1 \mathrm{~N}-2$-hydroxyethylpiperazine- $N$ '-2-ethanesulfonic acid, $0.1 \% \mathrm{BSA}$ and $1 \mathrm{mmol} / \mathrm{l}$ glucose. Each incubation vial contained 12 islets in $1.0 \mathrm{ml} \mathrm{KRB}$ and was treated with $95 \% \quad \mathrm{O}_{2} / 5 \% \quad \mathrm{CO}_{2}$ to obtain constant $\mathrm{pH}$ and oxygenation.

Insulin secretion in islets Preincubation was followed by $1 \mathrm{~h}$ incubation at $37^{\circ} \mathrm{C}$ in a metabolic shaker ( 30 cycles per min) in a medium containing either 1 or $20 \mathrm{mmol} / 1$ glucose. Insulin was then measured using a radioimmunoassay (Linco Research, Saint Charles, MO, USA).

RNA isolation Islets were cultured in CMRL 1066 (ICN Biomedicals, Costa Mesa, CA, USA) supplemented with $10 \mathrm{mmol} / \mathrm{l}$ HEPES, $2 \mathrm{mmol} / 1 \mathrm{~L}$-glutamine, $50 \mu \mathrm{g} / \mathrm{ml}$ gentamicin, $0.25 \mu \mathrm{g} / \mathrm{ml}$ fungizone (GIBCO, BRL, Gaithersburg, MD, USA), $20 \mu \mathrm{g} / \mathrm{ml}$ ciprofloxacin (Bayer Healthcare, Leverkusen, Germany) and $10 \mathrm{mmol} / \mathrm{l}$ nicotinamide at $37^{\circ} \mathrm{C}\left(5 \% \mathrm{CO}_{2}\right)$ for $1-9$ days prior to RNA preparation.
RNA was isolated from islets using the AllPrep DNA/RNA Mini Kit (Qiagen, Valencia, CA, USA). Concentration and purity were measured using a NanoDrop ND-1000 spectrophotometer $\left(A_{260} / A_{280}>1.8\right.$ and $\left.A_{260} / A_{230}>1.0\right)$ (NanoDrop Technologies, Wilmington, NC, USA). No signs of degradation were observed using agarose gel electrophoresis and Experion RNA gel chips (Bio-Rad, Hercules, CA, USA).

Microarray gene expression in human pancreatic islets The microarrays were performed following the Affymetrix standard protocol. Briefly, 100-200 ng total RNA was processed following the GeneChip Expression 3'-Amplification Reagents One-cycle cDNA synthesis kit instructions (Affymetrix, Santa Clara, CA, USA) to produce doublestranded cDNA, which was used as a template to generate biotin-targeted cRNA following the manufacturer's specifications. This was fragmented and hybridised onto the GeneChip Human Gene 1.0 ST whole transcript based assay overnight in the GeneChip Hybridisation oven 6400 using standard procedures. The arrays were washed and stained in a GeneChip Fluidics Station 450 and scanned with the GeneChip Scanner 3000. Image analysis was performed using GeneChip operating software. The array data were summarised and normalised with the robust multi-array analysis method using the Expression Console software (Affymetrix).

Quantitative PCR PAX6 and PCSK1 mRNA expression was confirmed using RT quantitative PCR. Reactions were performed in triplicate with three endogenous controls (ECs). Reverse transcription was performed on RNA samples using an Omniscript RT kit (Qiagen) and Oligo(dt) primers according to the manufacturers' instructions. Real-time quantitative PCR was carried out using TaqMan Gene Expression Assays (Applied Biosystems) according to the manufacturer's instructions. The following assays were used: PAX6 (assay id: Hs01088112_m1), PCSK1 (assay id: Hs00175619_m1), HPRT1 (EC) (assay id: 4326321E, VIC-MGB), PPIA (EC) (assay id: 4326316E, VIC-MGB) and POLR2A (EC) (assay id: Hs00172187_m1). The PCR reaction was monitored using an ABI PRISM 7700 Sequence Detector (Applied Biosystems).

Relative expression was calculated by normalising the expression $\left(2^{-\Delta \mathrm{C}_{\mathrm{t}}}\right)$ using the geometric mean of the EC as described in [25]. Correlation between microarray and quantitative PCR expression was 0.85 for $P A X 6$ and 0.97 for PCSK1.

Pathway analysis Pathway analysis was performed using GENECODIS [26, 27]. GO biological processes were searched at the lowest GO level. Hypergeometric tests and 
false discovery rate corrections were used to test for significance.

Statistical methods We estimated the effect of genetic variants on quantitative traits using linear regression correcting for sex, age and BMI in the PPP, HBCS and MM studies. The BPS (corrected residuals) was analysed in PLINK (http://pngu.mgh.harvard.edu/ purcell/plink/) [28] using the QFAM-total method with adaptive permutation to correct for family structure. Variables that were not normally distributed were log-transformed (natural) before analysis. Islet expression was analysed by Spearman correlation and multiple linear regression adjusted for the donor's sex, age, BMI and diabetes status.

All statistical analysis was performed with the Statistical Package for the Social Sciences version 17.0 (SPSS), PLINK version 1.06 [28] or $\mathrm{R}$ version 2.11.0. A twotailed $p$ value of 0.05 was considered significant. When the number of homozygous individuals allowed, both additive and recessive models were used and the $p$ values corrected for two tests by Bonferroni correction.

\section{Results}

Identification of candidate SNP rs685428 in the DGI genome-wide association study We analysed ten genotyped and 54 imputed SNPs in the PAX6 gene $\pm 50 \mathrm{kbp}$ in the DGI study, in which 1,361 non-diabetic individuals had insulin and 307 had proinsulin data available [17]. We found a linkage disequilibrium (LD) block $35 \mathrm{kbp}$ upstream of the PAX6 gene, tagged by the directly genotyped marker rs685428, where the minor $\mathrm{G}$ allele was associated with increased fasting insulin $\left(p=0.001, p_{\text {corrected }}=0.01\right)$ and increased HOMA-IR $\left(p=0.0008, p_{\text {corrected }}=0.008\right)$. The same marker was associated with a low fasting proinsulin/ insulin ratio ( $\left.p_{\text {additive model }}\left[p_{\text {add }}\right]=0.007\right)$. The effect was even stronger when applying a recessive rather than additive model (Table 2).

Gene expression in human pancreatic islets The associated LD block did not include the coding region of $P A X 6$, making it likely that the rs685428 variant or another SNP in the LD block could affect gene expression. We measured mRNA levels of PAX6 by quantitative PCR in islets from six diabetic and 42 non-diabetic human organ donors and related it to the PAX6 rs685428 genotype. We also measured PCSK1 expression, since PCSK1 is thought to be the mediator of the $P A X 6$ effect on proinsulin processing. $P A X 6$ and $P C S K 1$ expression correlated strongly $\left(R=0.72, p=5.43 \times 10^{-8}\right)$. PAX6 was slightly, although not significantly, lower in diabetic than non-diabetic individuals (Fig. 1a). The expression of
PCSK1 was lower in diabetic $(p=0.04)$ than non-diabetic islets (Fig. 1b). Both PAX6 and PCSK1 expression was lower in rs685428 AG than in AA individuals $(p=0.008$ and $p=0.001$ ). The fraction of variance explained by the SNP was 0.12 for $P A X 6$ and 0.14 for $P C S K 1$. We also analysed the correlation between $P A X 6$ and putative $P A X 6$ target genes involved in metabolic control: INS, SLC2A2, PCSK2, PDX1, $S S T$ and $G C G$ using microarray expression data from the same islet donors (Fig. 1c-h). All genes correlated with PAX6 expression and expression of INS, SLC2A2 and PDXI was decreased in diabetic individuals.

We next analysed cis-expression of ten other genes (DCDC5, DCDC1, DNAJC24, IMMP1L, ELP4, RCN1, $W T 1, E I F 3 M, C C D C 73$ and PRRG4) within a $2 \mathrm{Mb}$ region of the rs685428 SNP. None of these was differentially expressed between rs685428 AA and AG individuals $(p>0.05)$.

Genome-wide correlation with PAX6 expression We performed a co-expression analysis of genes in human islets showing correlation with $P A X 6$ at a genome-wide level to identify new potential PAX6 targets. Out of 22,201 genes represented on the microarray, 403 correlated with $P A X 6$ with a $p$ value $<2.25 \times 10^{-6}$, corresponding to a $p$ value of 0.05 after Bonferroni correction. An $R>0.75$ cut-off resulted in a list of 60 genes, all with $p$ values $<5 \times 10^{-9}$, including several key players in pancreatic development and function such as ISL1 and NEUROD1 (electronic supplementary material [ESM] Table 1). Interestingly, one of the strongest correlating genes was MEIS2 $(R=0.84)$, which regulates PAX6 expression during lens development (Fig. 1i) [29]. MEIS2 expression was lower in AG than AA genotype carriers of the $P A X 6$ variant ( $p=0.04$; Fig. $1 j$ ). Pathway analysis of the top 60 genes showed an over-representation of genes involved in signal transduction (ten genes), regulation of transcription (seven genes), ion transport (seven genes) and synaptic transmission (six genes).

The PAX6 rs685428 genotype influences fasting insulin levels and fasting proinsulin/insulin ratio The effect of the rs $685428 \mathrm{G}$ allele on fasting insulin could be replicated in the additional cohorts ( $p_{\text {recessive model }}\left[p_{\text {rec }}\right]=0.02$ in meta-analysis) and HOMA-IR ( $p_{\text {rec }}=0.02$, meta-analysis). In a meta-analysis of all studies, including the DGI, GG homozygous individuals had $10 \%$ higher fasting insulin levels $\left(p_{\text {rec }}=0.0008\right)$ and HOMA-IR indices $\left(p_{\text {rec }}=0.0016\right)$ than AA/AG individuals (Table 2, Fig. 2). The $2 \mathrm{~h}$ insulin response to an OGTT was slightly increased $\left(p_{\text {add }}=0.04, p_{\text {rec }}=\right.$ 0.2 ) whereas glucose levels did not differ by genotype (Table 2).

We also searched the SNP results in the large metaanalysis performed by the Meta-analyses of Glucose and Insulin-related Traits Consortium (MAGIC) but found no 
Table 2 Association between rs685428 genotype and phenotypes

\begin{tabular}{|c|c|c|c|c|c|c|c|}
\hline \multirow[t]{2}{*}{ Phenotype } & \multirow[t]{2}{*}{$n$} & \multicolumn{3}{|l|}{ Additive model } & \multicolumn{3}{|c|}{ Recessive model (GG vs $\mathrm{AA}+\mathrm{AG})$} \\
\hline & & $\beta(\mathrm{SEM})$ & $p$ value & $p_{\text {corrected }}$ & $\beta(\mathrm{SEM})$ & $p$ value & $p_{\text {corrected }}$ \\
\hline \multicolumn{8}{|c|}{ Fasting proinsulin ${ }^{\mathrm{a}}$} \\
\hline DGI & 307 & $-0.11(0.053)$ & 0.04 & 0.08 & - & - & - \\
\hline РPP & 2,221 & $0.014(0.017)$ & 0.4 & 0.8 & $0.098(0.054)$ & 0.07 & 0.14 \\
\hline HBCS & 1,585 & $0.01(0.03)$ & 0.7 & 1 & $-0.015(0.046)$ & 0.7 & 1 \\
\hline Meta-analysis & 4,113 & $0.004(0.014)$ & 0.77 & 1 & $0.033(0.035)$ & 0.35 & 1 \\
\hline \multicolumn{8}{|l|}{ Fasting insulin ${ }^{\mathrm{a}}$} \\
\hline DGI & 1,361 & $0.17(0.054)$ & 0.001 & 0.002 & $0.78(0.21)$ & $1.6 \times 10^{-4}$ & $3.2 \times 10^{-4}$ \\
\hline PPP & 3,914 & $-0.001(0.016)$ & 1 & 1 & $0.12(0.052)$ & 0.02 & 0.04 \\
\hline HBCS & 1,586 & $0.056(0.027)$ & 0.04 & 0.08 & $0.11(0.046)$ & 0.02 & 0.04 \\
\hline BPS & 1,848 & $0.006(0.02)$ & 0.8 & 1 & $-0.056(0.068)$ & 0.4 & 0.8 \\
\hline Meta-analysis & 8,709 & $0.023(0.013)$ & 0.08 & 0.16 & $0.10(0.029)$ & 0.0004 & 0.0008 \\
\hline \multicolumn{8}{|c|}{ Proinsulin/insulin ratio ${ }^{\mathrm{a}}$} \\
\hline DGI & 307 & $-0.31(0.12)$ & 0.007 & 0.014 & - & - & - \\
\hline РPP & 2,191 & $0.006(0.020)$ & 0.8 & 1 & $-0.051(0.065)$ & 0.4 & 0.8 \\
\hline HBCS & 1,585 & $-0.05(0.025)$ & 0.07 & 0.14 & $-0.12(0.042)$ & 0.004 & 0.008 \\
\hline Meta-analysis & 4,083 & $-0.021(0.016)$ & 0.18 & 0.36 & $-0.10(0.035)$ & 0.004 & 0.008 \\
\hline \multicolumn{8}{|l|}{ Fasting glucose } \\
\hline DGI & 1,428 & $0.02(0.053)$ & 0.7 & 1 & $0.016(0.19)$ & 0.9 & 1 \\
\hline PPP & 3,982 & $-0.012(0.017)$ & 0.5 & 1 & $0.0030(0.056)$ & 1 & 1 \\
\hline HBCS & 1,586 & $0.038(0.026)$ & 0.2 & 0.4 & $0.066(0.044)$ & 0.1 & 0.2 \\
\hline BPS & 1,848 & $-0.024(0.025)$ & 0.5 & 1 & $-0.054(0.08)$ & 0.5 & 1 \\
\hline Meta-analysis & 8,844 & $-0.002(0.11)$ & 0.84 & 1 & $0.037(0.038)$ & 0.40 & 0.8 \\
\hline \multicolumn{8}{|l|}{ HOMA-IR ${ }^{\mathrm{a}}$} \\
\hline DGI & 1,366 & $0.18(0.053)$ & $7.8 \times 10^{-4}$ & $1.6 \times 10^{-3}$ & $0.79(0.2)$ & $6.7 \times 10^{-5}$ & $1.3 \times 10^{-4}$ \\
\hline РPP & 3,912 & $-0.003(0.016)$ & 0.8 & 1 & $0.12(0.055)$ & 0.02 & 0.04 \\
\hline HBCS & 1,586 & $0.062(0.029)$ & 0.03 & 0.06 & $0.12(0.048)$ & 0.02 & 0.04 \\
\hline BPS & 1,848 & $0.0044(0.02)$ & 1 & 1 & $-0.060(0.068)$ & 0.4 & 0.8 \\
\hline Meta-analysis & 8,712 & $0.017(0.011)$ & 0.12 & 0.24 & $0.098(0.031)$ & 0.0006 & 0.0012 \\
\hline \multicolumn{8}{|l|}{$2 \mathrm{~h}$ insulin $^{\mathrm{a}}$} \\
\hline DGI & 1,010 & $0.075(0.063)$ & 0.24 & 0.48 & $-0.016(0.24)$ & 0.5 & 1 \\
\hline РPP & 3,802 & $0.033(0.024)$ & 0.17 & 0.35 & $0.12(0.081)$ & 0.15 & 0.31 \\
\hline $\mathrm{HBCS}$ & 1,586 & $0.049(0.035)$ & 0.17 & 0.34 & $0.047(0.059)$ & 0.42 & 0.84 \\
\hline BPS & 1,848 & $0.032(0.035)$ & 0.38 & 0.76 & $0.12(0.12)$ & 0.3 & 0.6 \\
\hline Meta-analysis & 8,246 & $0.039(0.017)$ & 0.018 & 0.036 & $0.070(0.043)$ & 0.11 & 0.22 \\
\hline \multicolumn{8}{|l|}{$2 \mathrm{~h}$ glucose } \\
\hline DGI & 1,410 & $-0.038(0.053)$ & 0.47 & 0.94 & $0.087(0.019)$ & 0.065 & 0.13 \\
\hline РPP & 3,958 & $0.082(0.045)$ & 0.07 & 0.14 & $0.18(0.152)$ & 0.25 & 0.5 \\
\hline $\mathrm{HBCS}$ & 1,586 & $0.046(0.084)$ & 0.59 & 1 & $-0.036(0.14)$ & 0.8 & 1 \\
\hline BPS & 1,848 & $0.036(0.065)$ & 1 & 1 & $0.25(0.21)$ & 0.23 & 0.46 \\
\hline Meta-analysis & 8,802 & $0.034(0.029)$ & 0.23 & 0.46 & $0.095(0.083)$ & 0.25 & 0.5 \\
\hline \multicolumn{8}{|l|}{$\mathrm{CIR}^{\mathrm{a}}$} \\
\hline DGI & 947 & $0.15(0.064)$ & 0.019 & 0.038 & $0.18(0.24)$ & 0.45 & 0.9 \\
\hline РPP & 4,187 & $0.034(0.022)$ & 0.14 & 0.27 & $0.15(0.076)$ & 0.045 & 0.09 \\
\hline HBCS & 1,579 & $-0.031(0.038)$ & 0.42 & 0.84 & $0.061(0.063)$ & 0.33 & 0.66 \\
\hline BPS & 1,848 & $-0.0003(0.034)$ & 1 & 1 & $-0.043(0.11)$ & 0.7 & 1 \\
\hline Meta-analysis & 8,561 & $0.022(0.016)$ & 0.17 & 0.34 & $0.079(0.043)$ & 0.071 & 0.14 \\
\hline
\end{tabular}

${ }^{\mathrm{a}} \log _{\mathrm{e}}$ transformed

CIR, corrected insulin response 
Fig. 1 Relative expression of PAX6 and target genes in human pancreatic islets. a Expression of $P A X 6$ measured by quantitative PCR. Whereas the mRNA expression of $P A X 6$ was lower in AG $(n=13)$ than in AA genotype carriers $(n=33)$, the mRNA of PAX6 was not significantly reduced in diabetic (T2D) $(n=6)$ vs non-diabetic islets $(n=42)$. b PCSK 1 expression was lower both in G allele carriers and in islets from diabetic patients. $\mathbf{c}-\mathbf{h}$ Expression of suggested PAX6 target genes in human pancreatic islets measured by microarray. $\mathbf{i}$ MEIS2 expression correlated strongly with PAX6 $(R=0.84)$ in human pancreatic islets. Filled circles are AA homozygous, open circles are AG heterozygous. $\mathbf{j}$ The mRNA expression of MEIS2 was lower in AG $(n=13)$ than in AA genotype carriers of the SNP rs685428 in the PAX6 gene. There was no significant difference in MEIS2 mRNA expression between islets from diabetic and non-diabetic cadaver donors. Error bars show SEM. ${ }^{*} p<0.05, * * p<0.01$. C, controls

significant association with fasting insulin $(p=0.3)$ nor HOMA-IR $(p=0.2)$ [30] However, since this study only used an additive model it does not exclude a recessive effect of the SNP.

To replicate the effect of rs 685428 on the proinsulin/ insulin ratio we analysed 2,191 individuals from the PPP-Botnia study and 1,585 from the HBCS, for whom proinsulin data was available. In the HBCS the proinsulin/insulin ratio was significantly lower in GG compared with AA homozygous individuals $\left(P_{\text {add }}=0.14\right.$, $P_{\text {rec }}=0.008$; Fig. 2b). A similar, non-significant trend was seen in the PPP-Botnia study. In a meta-analysis of all studies, GG genotype carriers had a $10 \%$ lower proinsulin/ insulin ratio $\left(p_{\text {rec }}=0.008\right)$ than AA/AG carriers (Table 2). There was no difference in total proinsulin levels $(P>0.3$, meta-analysis) [31].

Effect of PAX6 rs685428 on glucose and argininestimulated insulin secretion in vivo and in vitro We also studied the effect of rs685428 on arginine-stimulated insulin secretion in 167 Malmö men (Table 1) [21, 32]. The AIR to arginine was lower in AG/GG than in AA genotype carriers at all glucose concentrations $(p=0.04$; Fig. 3 a) whereas the slope of potentiation of insulin secretion by glucose did not significantly differ between the two genotype groups [31]. A meta-analysis of corrected insulin response in all studies was not significantly different (Table 2).

To link these effects directly to impaired glucosestimulated insulin secretion in vitro we investigated insulin secretion at low $(1 \mathrm{mmol} / \mathrm{l})$ and high $(16.7-20 \mathrm{mmol} / \mathrm{l})$ glucose in human islets. Insulin secretion was reduced in islets from AG vs AA genotype carriers at both high and low glucose $(p=0.002$ and $p=0.009$, respectively). Potassium-stimulated insulin secretion was also reduced in risk genotype carriers $(p=0.04$; Fig. $3 b)$. Further, we analysed the correlation between PAX6 and PCSK1 expression and $\mathrm{HbA}_{1 \mathrm{c}}$ and insulin secretion (Fig. 3c,d). Expression of $P A X 6$ was positively associated with insulin secretion $\left(r_{s}=0.46, p=0.004\right)$. A higher expression of
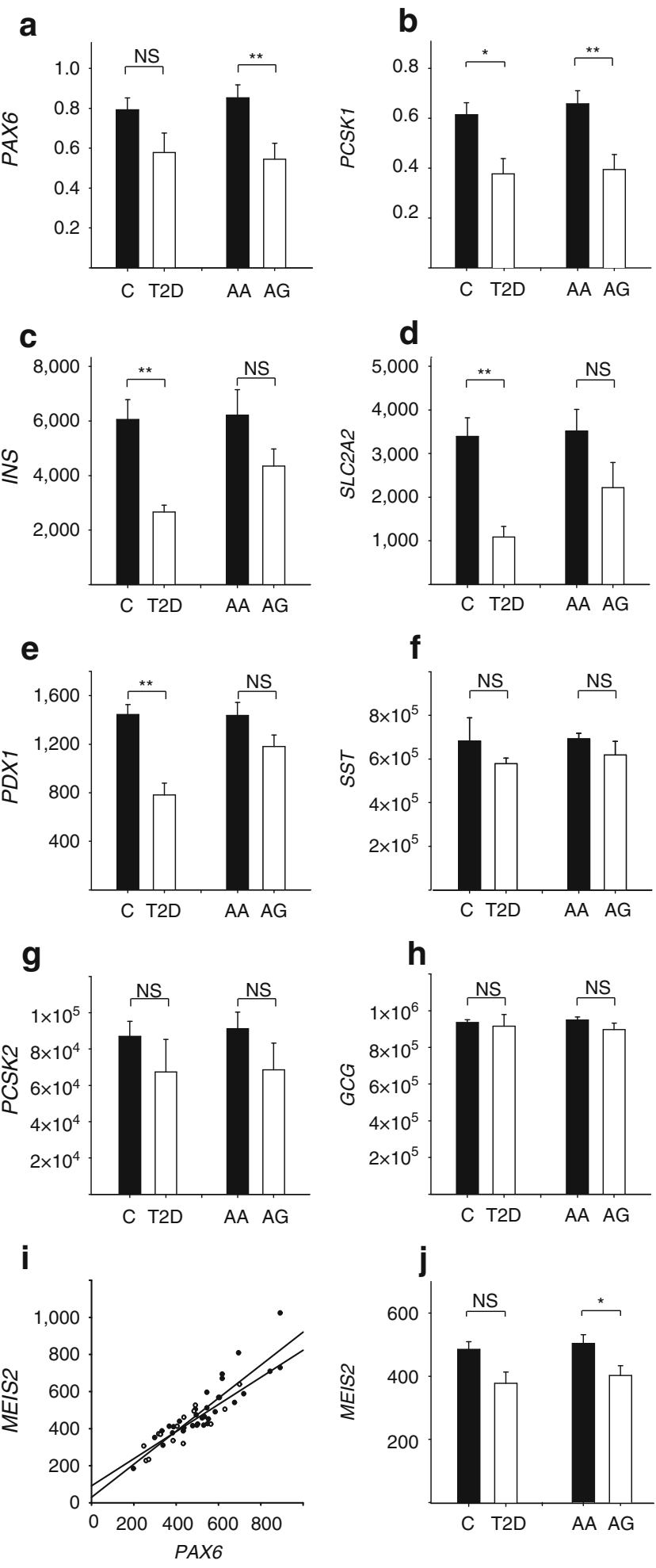

PCSK1 was associated with higher insulin secretion $\left(r_{s}=\right.$ $0.45, p=0.005)$ and lower $\mathrm{HbA}_{1 \mathrm{c}}\left(r_{s}=-0.34, p=0.04\right)$.

Effect of PAX6 rs685428 on plasma glucagon and GIP levels Next we measured plasma glucagon $(n=2,197)$ and GIP $(n=1,601)$ levels in a subset of the PPP study. 

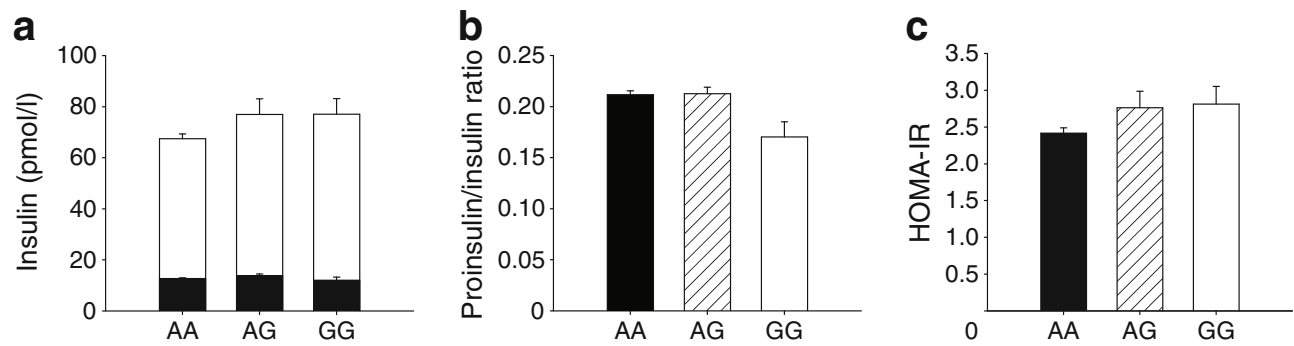

Fig. 2 a Fasting insulin levels in the HBCS study. The proinsulin level (black bars) was not significantly different between the genotype groups. Total insulin levels (white bars) were higher in rs685428 heterozygous and GG homozygous individuals than in AA homo- zygotes $(p=0.04)$. b The fasting proinsulin/insulin ratio was significantly lower in GG homozygous individuals $(p=0.008)$. c Insulin resistance estimated by HOMA-IR was higher in AG and GG individuals $(p=0.04)$. Error bars show SEM
The $\mathrm{G}$ allele was associated with lower fasting plasma glucagon levels $\left(p_{\text {add }}=0.04, p_{\text {rec }}=0.08\right.$; Fig. $\left.4 a\right)$. The glucagon/insulin ratio was lower in $\mathrm{G}$ allele carriers both in the fasting state $\left(p_{\text {add }}=0.006, p_{\text {rec }}=0.004\right)$ and at $2 \mathrm{~h}$ $\left(p_{\text {add }}=0.04, p_{\text {rec }}=0.32 ;\right.$ Fig $\left.4 \mathrm{~b}\right)$. Furthermore, $\mathrm{G}$ allele carriers displayed lower fasting GIP concentrations $\left(p_{\text {add }}=\right.$ $0.05, p_{\text {rec }}=0.5$; Fig. $4 \mathrm{c}$ ). These differences were not influenced by the prevailing glucose concentration.
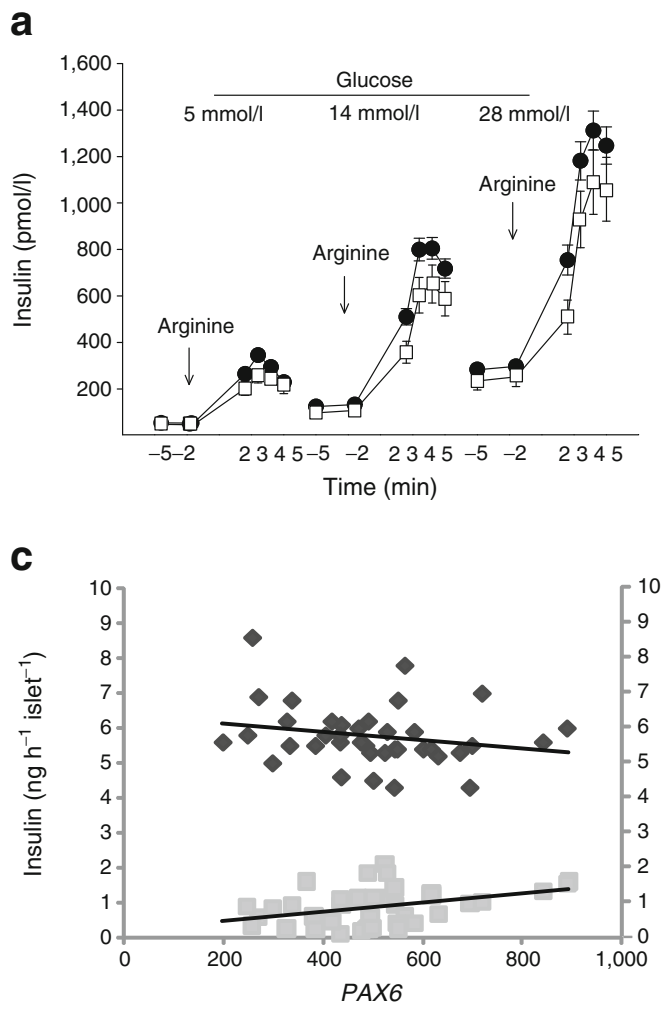

Fig. 3 a Insulin secretion in response to arginine stimulation at basal level $(5 \mathrm{mmol} / \mathrm{l})(p=0.02), 14 \mathrm{mmol} / \mathrm{l}(p=0.04)$ and $28 \mathrm{mmol} / 1 \quad(p=$ $0.04)$ glucose, in relation to SNP rs685428 in the PAX6 gene $\left(n_{\mathrm{AA}}=\right.$ $\left.127, n_{\mathrm{AB} / \mathrm{BB}}=40\right)$. b Insulin secretion from human islets in vitro in response to low $(1 \mathrm{mmol} / \mathrm{l})$ glucose $\left(n_{\mathrm{AA}}=22, n_{\mathrm{AB}}=8, p=0.002\right)$, high $(16.7-20 \mathrm{mmol} / \mathrm{l})$ glucose $\left(n_{\mathrm{AA}}=21, n_{\mathrm{AB}}=8, p=0.009\right)$ and high glucose plus $\mathrm{K}^{+}\left(16.7 \mathrm{mmol} / 1+70 \mathrm{mmol} / 1 \mathrm{~K}^{+}\right)\left(n_{\mathrm{AA}}=12, n_{\mathrm{AB}}=6, p=\right.$ $0.04)$. High glucose values were corrected for the differing glucose
Risk of type 2 diabetes The putative risk of developing type 2 diabetes for carriers of the rs685428 variant was analysed in all the cohorts studied ( $N=2,101$ cases/9,577 controls), and in the large Diabetes Genetics Replication and Meta-analysis Consortium (DIAGRAM + ) meta-analysis [33]. No significant association was seen in any of the cohorts (DGI with 1,464 cases and 1,467 controls: $p=0.7$, OR 0.96; DIAGRAM + with 2,832 cases and 15,843 controls: $p=0.5$,

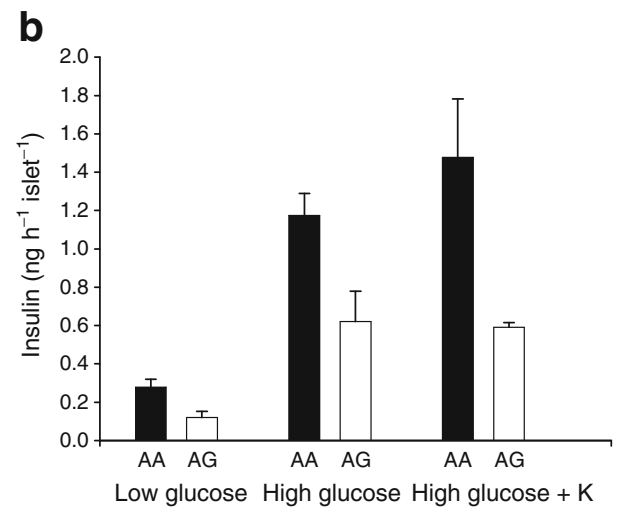

d

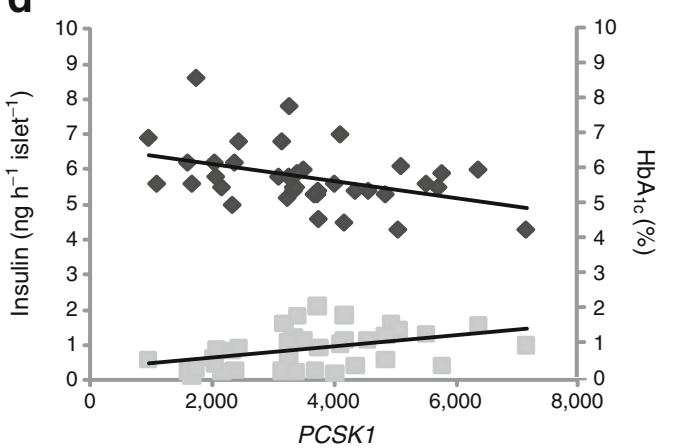

stimulation. c Correlation between $P A X 6$ expression and $\mathrm{HbA}_{1 \mathrm{c}}$ level $\left(r_{\mathrm{s}}=-0.26, p=0.1\right)$ and insulin secretion measured at $16.7 \mathrm{mmol} / 1$ glucose $\left(r_{\mathrm{s}}=0.46, p=0.004\right)$. d Correlation between PCSK1 expression and $\mathrm{HbA}_{1 \mathrm{c}}\left(r_{\mathrm{s}}=-0.34, p=0.04\right)$ and insulin secretion measured at $16.7 \mathrm{mmol} / 1$ glucose $\left(r_{\mathrm{s}}=0.45, p=0.005\right)$. Dark grey diamonds, $\mathrm{HbA}_{1 \mathrm{c}}$ results; light grey squares, insulin results. To convert values for $\mathrm{HbA}_{1 \mathrm{c}}$ in $\%$ to $\mathrm{mmol} / \mathrm{mol}$, subtract 2.15 and multiply by 10.929 . Error bars show SEM 

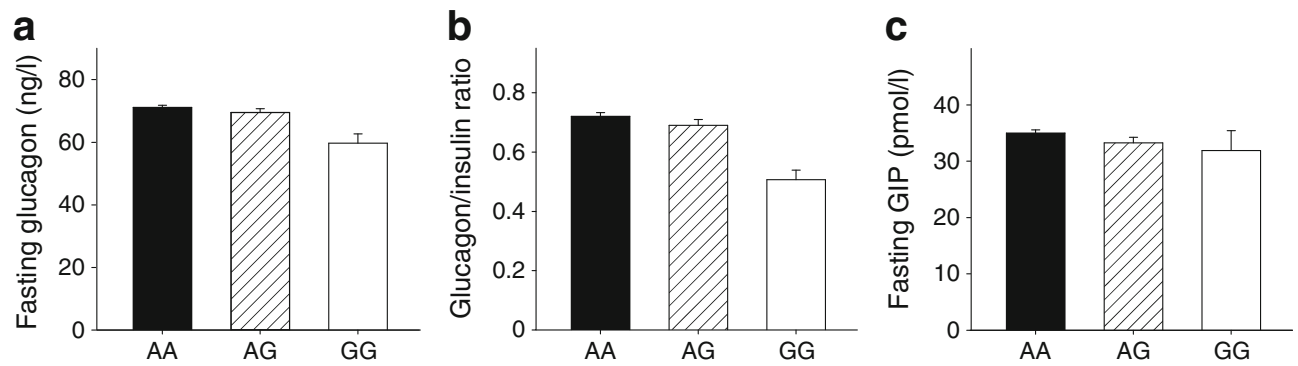

Fig. 4 a G allele carriers have lower levels of fasting serum glucagon compared with A allele carriers $(p=0.04)$. b Fasting glucagon/insulin molar ratio according to rs685428 genotype $(p=0.006)$. $\mathbf{c}$ Fasting serum
GIP concentration was also reduced in $\mathrm{G}$ allele carriers $(p=0.04)$. $p$ values are from linear regression analysis, additive model adjusted for sex, age and BMI. Error bars show SEM
OR 0.98; PPP with 215 cases and 4,116 controls: $p=0.2$, OR 0.77; BPS with 27 cases and 2,408 controls: $p=0.3$, OR 0.81 ; HBCS with 295 cases and 1,586 controls: $p=0.8$, OR 1.03) nor in a meta-analysis of all cohorts (4,933 cases and 25,420 controls, $p_{\text {meta }}=0.3$, OR 0.97).

\section{Discussion}

In this study we demonstrated that a common variant in the PAX6 gene was associated with marked changes in expression of key genes in human islets and thereby altered islet function. The similarity of effects in vivo and in vitro in human islets provides strong support for the central role of $P A X 6$ in development of islet function and regulation of glucose metabolism.

The finding that low $P A X 6$ expression causes impaired insulin secretion and affects glucose metabolism is in line with previously published findings in both animal models and human families with protein-altering mutations in the $P A X 6$ gene [4-7]. However, these studies were performed in individuals with more severe mutations making generalisation of the findings to potential effects of common variants in the gene difficult. Further, there is evidence from mouse models that the effect of mutations and deletions in Pax6 on pancreatic development depends upon which functional domain of the protein is affected [34].

Three studies have previously evaluated whether common variants in the $P A X 6$ gene affect risk of type 2 diabetes, analysing two, four and eight SNPs, respectively, but none of them found any significant association [35-37]. Although risk genotype carriers showed impaired insulin response to several secretagogues we could not detect any association with type 2 diabetes. It should be noted that only additive models were tested and that the strongest effect of the SNP was seen using a recessive model. A recessive effect on diabetes can thus not be excluded. Another explanation for this finding is that there are mechanisms that neutralise the effect of impaired insulin secretion on risk of diabetes. One such mechanism could be the decreased glucagon concen- trations in risk genotype carriers. Glucagon, particularly an increased glucagon/insulin ratio, has been ascribed a role in the pathogenesis of type 2 diabetes [38-40]. Here we observed decreased glucagon levels as well as a markedly decreased glucagon/insulin ratio in G allele carriers, suggesting that altered alpha cell function could contribute to the decreased risk of type 2 diabetes seen in $G$ allele carriers.

A high proinsulin/insulin ratio can indicate a defect in prohormone processing or beta cell stress due to insulin resistance, and elevated proinsulin levels predict future type 2 diabetes [40-42]. Impaired proinsulin processing was expected in risk allele carriers based upon the concomitant decrease in expression of genes encoding the proinsulin processing enzymes PCSK1 and PCSK2. This was also the case in the family study by Wen et al. where an elevated proinsulin/insulin ratio was associated with a decreased expression of PCSK1 [6]. In contrast, in the present study risk allele carriers showed a decreased proinsulin/insulin ratio despite lower mRNA levels of both PCSK1 and PCSK2. There might be several explanations for this unprecedented finding. One explanation is that the decrease in proinsulin/ insulin ratio reflects the change in the denominator, that is increased insulin levels, rather than altered proinsulin processing. This is supported by a lack of difference in proinsulin concentrations between different genotype carriers.

While the effects of $P A X 6$ on islet gene expression and function were expected, the increase in fasting insulin concentration is less obvious. To the former, decreased expression of $P A X 6$ was associated with decreased expression of PDX1, ISL1, NEUROD and MEIS2. The strong correlation between $P A X 6$ and MEIS2 expression is particularly interesting since Meis homeobox 2 (MEIS2) has been shown to act as a direct upstream regulator of $P A X 6$ expression during lens development [29]. MEIS binding sites have also been demonstrated in a PAX6 transcription enhancer element involved in pancreatic development [43]. MEIS2 could thus also be a major regulator of PAX6 transcription in the pancreas, possibly acting directly on the $P A X 6$ gene. However, more detailed investigation is required to determine whether these genes are targets or regulators of 
PAX6 expression or regulated by common upstream factors. If the $P A X 6$ polymorphism changes the islet cell ratio, as is seen in mouse models with mutated Pax6 [34], this could also contribute to the many correlations.

The most common cause for an increase in fasting insulin concentration is insulin resistance, also evidenced by an increase in the HOMA-IR. There is, however, no obvious explanation for a direct effect of the SNP on insulin sensitivity, nor did we see an effect of the SNP on insulin sensitivity measured during a euglycaemic-hyperinsulinaemic clamp in the MM study. In addition, no effect on insulin sensitivity was reported in mice with a truncated Pax6 gene [6]. We are thus left with the possibility that the increase in fasting insulin levels is unrelated to insulin resistance and possibly the result of an altered feedback loop in islets, for example altered clearance of insulin.

In conclusion, a common variant in PAX6 is associated with reduced PAX6 and PCSK1 expression in human islets, reduced insulin response and decreased glucagon and GIP concentrations. The impairment in insulin response was not translated into an increased risk of type 2 diabetes. These findings emphasise the central role of the PAX6 gene in the regulation of islet function and glucose metabolism in man.

Acknowledgements This study was supported by Linnéus and Exodiab grants from the Swedish Research Council; grants from the Novo Nordisk foundation, Swedish Diabetes Research foundation, Wallenberg foundation, Lundberg foundation, Söderberg foundation, Sigrid Juselius and Folkhälsan foundations; as well as by the EU Framework 7 CEED3 grant. We are grateful to the DIAGRAM and MAGIC consortia for allowing us to use their databases to search for the potential effect of the PAX6 SNP on association with type 2 diabetes, fasting insulin and HOMA-IR. We also thank C.B. Wollheim, University of Geneva, for constructive criticism of the manuscript.

Contribution statement EA: Study coordination and design, genotyping, statistical analysis, data interpretation and draft of the manuscript. FT: Genotyping, real-time PCR and statistical analysis. STL: Microarray analysis. JT: Generation and analysis of microarray and insulin secretion data. YZ: Real-time PCR and analysis. PA: Statistical analysis. OH: Analysis of expression data. BI and TT: Sample collection, phenotyping (Botnia) and data interpretation. KE: Phenotyping in the MM study and data interpretation. JGE: Phenotyping (HBCS) and data interpretation. VL: DGI genome-wide association study and study design, data interpretation and study supervision. LG: Study conception and design, data interpretation, study supervision and draft of the manuscript. All authors critically revised the draft and approved the final manuscript.

Duality of interest The authors declare that there is no duality of interest associated with this manuscript.

\section{References}

1. Sander M, Neubuser A, Kalamaras J, Ee HC, Martin GR, German MS (1997) Genetic analysis reveals that PAX6 is required for normal transcription of pancreatic hormone genes and islet development. Genes Dev 11:1662-1673
2. Ritz-Laser B, Estreicher A, Gauthier BR, Mamin A, Edlund H, Philippe J (2002) The pancreatic beta-cell-specific transcription factor Pax-4 inhibits glucagon gene expression through Pax-6. Diabetologia 45:97-107

3. Glaser T, Walton DS, Maas RL (1992) Genomic structure, evolutionary conservation and aniridia mutations in the human PAX6 gene. Nat Genet 2:232-239

4. Nishi M, Sasahara M, Shono T et al (2005) A case of novel de novo paired box gene 6 (PAX6) mutation with early-onset diabetes mellitus and aniridia. Diabet Med 22:641-644

5. Yasuda T, Kajimoto Y, Fujitani Y et al (2002) PAX6 mutation as a genetic factor common to aniridia and glucose intolerance. Diabetes 51:224-230

6. Wen JH, Chen YY, Song SJ et al (2009) Paired box 6 (PAX6) regulates glucose metabolism via proinsulin processing mediated by prohormone convertase 1/3 (PC1/3). Diabetologia 52:504-513

7. Ashery-Padan R, Zhou X, Marquardt T et al (2004) Conditional inactivation of Pax6 in the pancreas causes early onset of diabetes. Dev Biol 269:479-488

8. Larsson LIS-OL, Hougaard DM, Sosa-Pineda B, Gruss P (1998) Pax 4 and 6 regulate gastrointestinal endocrine cell development. Mech Dev 79:153-159

9. Fujita Y, Chui JW, King DS et al (2008) Pax6 and Pdx1 are required for production of glucose-dependent insulinotropic polypeptide in proglucagon-expressing L cells. Am J Physiol Endocrinol Metab 295:E648-E657

10. Ritz-Laser B, Estreicher A, Klages N, Saule S, Philippe J (1999) Pax- 6 and $C d x-2 / 3$ interact to activate glucagon gene expression on the G1 control element. J Biol Chem 274:4124-4132

11. Katz LS, Gosmain Y, Marthinet E, Philippe J (2009) Pax6 regulates the proglucagon processing enzyme $\mathrm{PC} 2$ and its chaperone 7B2. Mol Cell Biol 29:2322-2334

12. Ugleholdt R, Poulsen ML, Holst PJ et al (2006) Prohormone convertase $1 / 3$ is essential for processing of the glucose-dependent insulinotropic polypeptide precursor. J Biol Chem 281:11050 11057

13. Ugleholdt R, Zhu X, Deacon CF, Orskov C, Steiner DF, Holst JJ (2004) Impaired intestinal proglucagon processing in mice lacking prohormone convertase 1. Endocrinology 145:1349-1355

14. Ding J, Gao Y, Zhao J et al (2009) Pax6 haploinsufficiency causes abnormal metabolic homeostasis by down-regulating glucagonlike peptide 1 in mice. Endocrinology 150:2136-2144

15. Kaneto H, Matsuoka TA, Miyatsuka T et al (2008) PDX-1 functions as a master factor in the pancreas. Front Biosci 13:6406-6420

16. Guillam MT, Hummler E, Schaerer E et al (1997) Early diabetes and abnormal postnatal pancreatic islet development in mice lacking Glut-2. Nat Genet 17:327-330

17. Saxena R, Voight BF, Lyssenko V et al (2007) Genome-wide association analysis identifies loci for type 2 diabetes and triglyceride levels. Science 316:1331-1336

18. Eriksson JG, Osmond C, Kajantie E, Forsen TJ, Barker DJ (2006) Patterns of growth among children who later develop type 2 diabetes or its risk factors. Diabetologia 49:2853-2858

19. Eriksson KF, Lindgarde F (1990) Impaired glucose tolerance in a middle-aged male urban population: a new approach for identifying high-risk cases. Diabetologia 33:526-531

20. Eriksson KF, Lindgarde F (1991) Prevention of type 2 (noninsulin-dependent) diabetes mellitus by diet and physical exercise. The 6-year Malmo feasibility study. Diabetologia 34:891-898

21. Tripathy D, Eriksson KF, Orho-Melander M, Fredriksson J, Ahlqvist G, Groop L (2004) Parallel manifestation of insulin resistance and beta cell decompensation is compatible with a common defect in type 2 diabetes. Diabetologia 47:782-793

22. Sobey WJ, Beer SF, Carrington CA et al (1989) Sensitive and specific two-site immunoradiometric assays for human insulin, 
proinsulin, 65-66 split and 32-33 split proinsulins. Biochem J 260:535-541

23. Lyssenko V, Nagorny CL, Erdos MR et al (2009) Common variant in MTNR1B associated with increased risk of type 2 diabetes and impaired early insulin secretion. Nat Genet 41:82-88

24. Sluiter WJ, Erkelens DW, Reitsma WD, Doorenbos H (1976) Glucose tolerance and insulin release, a mathematical approach I. Assay of the beta-cell response after oral glucose loading. Diabetes 25:241-244

25. Vandesompele J, de Preter K, Pattyn F, et al. (2002) Accurate normalization of real-time quantitative RT-PCR data by geometric averaging of multiple internal control genes. Genome Biol 3: RESEARCH0034

26. Carmona-Saez P, Chagoyen M, Tirado F, Carazo JM, PascualMontano A (2007) GENECODIS: a web-based tool for finding significant concurrent annotations in gene lists. Genome Biol 8:R3

27. Nogales-Cadenas R, Carmona-Saez P, Vazquez M et al (2009) GeneCodis: interpreting gene lists through enrichment analysis and integration of diverse biological information. Nucleic Acids Res 37:W317-W322

28. Purcell S, Neale B, Todd-Brown K et al (2007) PLINK: a tool set for whole-genome association and population-based linkage analyses. Am J Hum Genet 81:559-575

29. Zhang X, Friedman A, Heaney S, Purcell P, Maas RL (2002) Meis homeoproteins directly regulate Pax6 during vertebrate lens morphogenesis. Genes Dev 16:2097-2107

30. Dupuis J, Langenberg C, Prokopenko I et al (2010) New genetic loci implicated in fasting glucose homeostasis and their impact on type 2 diabetes risk. Nat Genet 42:105-116

31. Ward WK, Bolgiano DC, McKnight B, Halter JB, Porte D Jr (1984) Diminished B cell secretory capacity in patients with noninsulindependent diabetes mellitus. J Clin Invest 74:1318-1328

32. Carlsson A, Sundkvist G, Groop L, Tuomi T (2000) Insulin and glucagon secretion in patients with slowly progressing autoimmune diabetes (LADA). J Clin Endocrinol Metab 85:76-80
33. Voight BF, Scott LJ, Steinthorsdottir V et al (2010) Twelve type 2 diabetes susceptibility loci identified through large-scale association analysis. Nat Genet 42:579-589

34. Dames P, Puff R, Weise M et al (2010) Relative roles of the different Pax6 domains for pancreatic alpha cell development. BMC Dev Biol 10:39

35. Yokoi N, Kanamori M, Horikawa Y et al (2006) Association studies of variants in the genes involved in pancreatic beta-cell function in type 2 diabetes in Japanese subjects. Diabetes 55:2379-2386

36. Gaulton KJ, Willer CJ, Li Y et al (2008) Comprehensive association study of type 2 diabetes and related quantitative traits with 222 candidate genes. Diabetes 57:3136-3144

37. Sandhu MS, Weedon MN, Fawcett KA et al (2007) Common variants in WFS1 confer risk of type 2 diabetes. Nat Genet 39:951-953

38. Unger RH, Orci L (1975) The essential role of glucagon in the pathogenesis of diabetes mellitus. Lancet 1:14-16

39. Goke B (2008) Islet cell function: alpha and beta cells - partners towards normoglycaemia. Int J Clin Pract Suppl 159:2-7

40. Roder ME, Porte D Jr, Schwartz RS, Kahn SE (1998) Disproportionately elevated proinsulin levels reflect the degree of impaired B cell secretory capacity in patients with noninsulin-dependent diabetes mellitus. J Clin Endocrinol Metab 83:604-608

41. Wareham NJ, Byrne CD, Williams R, Day NE, Hales CN (1999) Fasting proinsulin concentrations predict the development of type 2 diabetes. Diabetes Care 22:262-270

42. Hanley AJ, D'Agostino R Jr, Wagenknecht LE et al (2002) Increased proinsulin levels and decreased acute insulin response independently predict the incidence of type 2 diabetes in the insulin resistance atherosclerosis study. Diabetes 51:12631270

43. Zhang X, Rowan S, Yue Y et al (2006) Pax6 is regulated by Meis and $\mathrm{Pbx}$ homeoproteins during pancreatic development. Dev Biol 300:748-757 